\title{
Comparative analysis of newly introduced disinfectants in hospitals in India: An important aspect of infection control policy
}

\author{
Tuhina Banerjee, Joel Filgona, Shampa Anupurba \\ Institute of Medical sciences, Department of Microbiology, India
}

\begin{abstract}
The effective use of disinfectants constitute an important factor in preventing hospital acquired infections. This study was undertaken to compare the effects of three newly introduced disinfectants in a number of tertiary care hospitals in India, namely superoxidized water (SOW) and two quaternary ammonium compounds (QACs), against the effects of $70 \%$ ethyl alcohol as one of the most commonly used disinfectants. All the disinfectants were tested for their effectiveness against multidrug resistant (MDR) Pseudomonas aeruginosa, meticillin resistant Staphylococcus aureus (MRSA) and vancomycin resistant enterococci (VRE). Suspension of $\geq 10^{6}$ bacteria was subjected to the action of different disinfectants for different length of time and in presence and absence of organic matter. Reduction in colony count was noted by semiquantitative surface viable colony count method. Results were expressed as percentage reductions and analyzed statistically. SOW showed good activity against most of the isolates, except against MRSA in presence of organic matter, where QACs were better. The disinfectants varied in their effects towards different organisms in different environmental conditions and with varying exposure time. Therefore, disinfection policies should take into consideration the type of ward and surfaces to be disinfected along with reasons for disinfection for an effective step towards infection control.
\end{abstract}

Key words

Cross infection and prevention and control; Hospitals; Disinfectants; India

\section{Corresponding Author}

Shampa Anupurba

Institute of Medical sciences, Department of Microbiology, India

Email: shampa_anupurba@yahoo.co.in 


\section{Introduction}

The increasing emergence and spread of multiresistant bacteria in hospitals still continues to challenge infection control practices worldwide. ${ }^{1}$ In spite of all efforts to improve hospital hygiene, nosocomial infections still pose a substantial risk to patients and added burden to hospitals. ${ }^{2}$ Studies suggest that routine use of disinfectants to disinfect hospital floors and other surfaces is not justified due to lack of evidence of their being involved directly in disease transmission. ${ }^{3}$ Though this environmental aspect of infection control is still controversial, during outbreaks observational evidence suggest definite role of surface transmission based on type of organisms contaminating the surfaces. In this regard there is sufficient data to show that inanimate environment serves as a secondary source for C. difficile, meticillin resistant Staphylococcus aureus (MRSA) and vancomycin resistant enterococci (VRE). ${ }^{4}$

For proper assessment of hospital cleaning, various microbiological standards have been proposed. MRSA, VRE and multidrug resistant Gram negative bacilli are among the possible indicator organisms. ${ }^{5}$ Cross-transmission of Gram-negative pathogens has been reported to vary between 5 and $23.3 \%$ which in comparison is significantly lower than $S$. aureus and enterococci, which have transmission rates of up to $50 \% .{ }^{1}$ Clearly, hospital disinfection policies have a major contribution in the control of hospital associated infections.

This study was undertaken to compare the effects of three newly introduced disinfectants in tertiary care centres in India against the above mentioned organisms and to compare their effects against the activity of $70 \%$ ethyl alcohol, a common surface disinfectant and ingredient of hand rub.

\section{Materials and Methods Indicator organisms}

Isolates of multidrug resistant (MDR) Pseudomonas aeruginosa, MRSA and VRE obtained from various sites like bed rails, side table, floor, ventilator tube, hand wash basin in the ICU environment and various indoor units were selected. Five strains of each type of organism were mixed and bacterial suspensions containing approximately $10^{6} \mathrm{cfu} / \mathrm{ml}$ were prepared for each of the organisms and serial 10-fold dilutions in normal saline made.

\section{Disinfectants tested}

Three newly introduced commercially prepared disinfectants with known efficacy namely superoxidized water (SOW, Sterisol, Faith Innovations, India) and two quaternary ammonium compounds with active ingredients didecyl dimethyl ammonium chloride (R25, Lonzagard DR 25aN, Lonza, India) in one and mixture of octyl decyl dimethyl ammonium chloride, dioctyl decyl dimethyl ammonium chloride, didecyl dimethyl ammonium chloride and alkyl dimethyl benzyl ammonium chloride (R82, Lonzagard R-82, Lonza, India) in the other were tested against the activities of $70 \%$ ethyl alcohol. All these products were tested in concentrations as per manufacturer's recommendations ( $1 \%$ for R-25, 2\% for R-82 and freshly generated sterisol in sterigen system for SOW).

\section{Test procedures}

The methodology followed was as given elsewhere with some modification. ${ }^{6}$

Briefly, at the start of the experiment the test strains were suspended in normal saline and turbidity adjusted visually to $0.5 \mathrm{Mc}$ Farland standard. These suspensions were then diluted hundred fold in normal saline to give a final concentration of $\geq 10^{6} \mathrm{cfu} / \mathrm{ml}$. Further in order to determine the exact initial cell concentration, for all the three organisms, spread plating on nutrient agar was performed on dilutions $10^{-4}-10^{-6}$. The experiment was performed in $5 \mathrm{ml}$ tubes, using four kinds of disinfectants mentioned above. Four different contact times $0.5 \mathrm{~min}, 1 \mathrm{~min}, 5 \mathrm{~min}, 10 \mathrm{~min}$ were tested. For each tube, $0.1 \mathrm{ml}$ of culture solution was added into $0.9 \mathrm{ml}$ of disinfectant. After certain contact time, a $5000 \mathrm{rpm}$ centrifuge was performed for $5 \mathrm{~min}$ to separate the culture from the solution. Supernatant was discarded and then the tube was refilled by respective neutralizing solutions namely $1 \%$ sodium thiosulphate for SOW and Tween 80 for the QACs, followed by spread plating on nutrient agar of each tube. The same set of experiments was repeated in presence of organic matter by adding the disinfectants to a mixture of $0.1 \mathrm{ml}$ of organism suspension and 0.1 $\mathrm{ml}$ of $5 \%(\mathrm{w} / \mathrm{v})$ autoclaved yeast suspension to simulate soiled conditions. Colonies were enumerated using a 
'semiquantitative surface viable count' method. Each experiment was done in triplicate and average number of colonies were considered for analysis.

\section{Statistical analysis}

Data were reported as reduction in colony counts based on different exposure times in absence and presence of organic matter. The data was analyzed using SPSS software. Analysis of variance (one way ANOVA) was carried out in order to evaluate whether the type of organism and disinfectants used showed any statistically significant impact on percentage reduction of colony counts.

\section{Results}

The results were expressed as percentage of bacterial colony count reduction after $0.5,1,5$ and $10 \mathrm{~min}$ exposure with each disinfectant in clean conditions and after 5 and 10 min in soiled conditions (tables I and II). The comparative analysis in this study showed that R82 and SOW were more effective on MDR Pseudomonas aeruginosa $(\mathrm{P}<0.05)$ than $70 \%$ ethyl alcohol and R25. The results were same even in the presence of organic matter. All the disinfectants had approximately similar effect against MRSA but presence of organic matter significantly reduced the effects of SOW against MRSA compared to others. In such conditions, both the QACs were better options. Oneway ANOVA result showed that there was no significant difference in the effect of these disinfectants on VRE ( $P>0.05)$. However, least significant difference (LSD) showed that $70 \%$ ethyl alcohol, R82 and SOW were better compared to R25 on surfaces contaminated with VRE without any visible soiling. Among the disinfectants tested, SOW showed maximum reduction in bacterial count at different exposure times.

Table I. Percentage (\%) reduction in bacterial colony counts due to the effects of the disinfectants

\begin{tabular}{|c|c|c|c|c|c|c|c|c|c|c|c|c|}
\hline \multirow{3}{*}{ Disinfectants } & \multicolumn{4}{|c|}{ MDR Pseudomonas sp } & \multicolumn{4}{|c|}{ MRSA } & \multicolumn{4}{|l|}{ VRE } \\
\hline & \multicolumn{4}{|c|}{ Contact time (in mins) } & \multicolumn{4}{|c|}{ Contact time (in mins) } & \multicolumn{4}{|c|}{ Contact time (in mins) } \\
\hline & 0.5 & 1 & 5 & 10 & 0.5 & 1 & 5 & 10 & 0.5 & 1 & 5 & 10 \\
\hline SOW & 99.9 & 99.8 & 99.8 & 99.8 & 99 & 99.9 & 90.2 & 98.7 & 99.9 & 99.9 & 99.9 & 99.9 \\
\hline R82 & 99.9 & 99.9 & 99.9 & 85 & 99.9 & 99.9 & 99.9 & 93.8 & 98.5 & 97.5 & 99.9 & 99.9 \\
\hline R25 & 88.3 & 68.8 & 79.2 & 68.8 & 99.9 & 99.9 & 99.9 & 99.9 & 99.9 & 99.9 & 66.5 & 55 \\
\hline $70 \%$ alcohol & 78.6 & 73.2 & 70 & 68 & 99.9 & 99.9 & 89.7 & 94.8 & 99 & 99.9 & 99.9 & 99.9 \\
\hline
\end{tabular}

Table II. Percentage (\%) reduction in bacterial colony counts in presence of organic matter ( $5 \% \mathrm{w} / \mathrm{v}$ yeast suspension)

\begin{tabular}{lrrrrrr} 
& \multicolumn{1}{l}{ MDR Pseudomonas sp } & \multicolumn{2}{l}{ MRSA } & \multicolumn{2}{l}{ VRE } \\
\cline { 2 - 7 } Disinfectants & Contact time (in mins) & \multicolumn{1}{c}{ Contact time (in mins) } & Contact time (in mins) \\
\cline { 2 - 7 } & 1 & 5 & 1 & 5 & 1 & 5 \\
\hline SOW & 99.6 & 98.4 & 69 & 57.6 & 97.7 & 68.9 \\
\hline R82 & 90.4 & 93.4 & 99.9 & 99.9 & 97.5 & 99.9 \\
\hline R25 & 89.6 & 79.2 & 99.9 & 99.9 & 68.5 & 50 \\
\hline 70\% alcohol & 50 & 44 & 99.9 & 96.9 & 99.6 & 99 \\
\hline
\end{tabular}




\section{Discussion}

Environmental surfaces near infected or colonized patients in hospitals are often contaminated by potentially pathogenic micro-organisms such as VRE and MRSA. Heavy contamination of the environment occurs from spillage of human secretions and excretions which require prompt cleaning and surface disinfection. ${ }^{7}$ In hospitals, surfaces with hand contact are often contaminated with nosocomial pathogens and may serve as vectors for cross transmission. The frequency of cross-transmission varies between 13 and $34.6 \%$, and is notably high in ICUs. ${ }^{8,}{ }^{9} \mathrm{~A}$ single hand contact with a contaminated surface results in a variable degree of pathogen transfer. Because compliance with hand hygiene is low worldwide, ${ }^{10}$ risk from contaminated surfaces is important.

In this study a comparative analysis of the effects of different newly introduced disinfectants was done. Of the two QACs tested, R82 had good activity against most of the organisms tested, while R25 was not highly effective on MDR Pseudomonas aeruginosa as compared to others. QACs are more expensive than chlorine and its derivatives, but they have numerous qualities that make them an attractive alternative. They are less affected by organic matter, they are not corrosive except at high concentrations, they are stable even in diluted solutions and concentrates, and can be stored for a long time without losing their antimicrobial activity. ${ }^{11}$ On the other hand, the heavy use of QACs has also been blamed for the dissemination of qac genes and the spread of efflux pumps. ${ }^{12}$ In the present study too, both the QACs were significantly better against MRSA in soiled environment. Therefore, in healthcare settings where prevalence of MRSA can be as high as $71 \%,{ }^{13}$ use of QACs has to be considered despite the risk of development of resistance.

SOW, though introduced long back in developed countries, is a new concept in India. The main advantage of this product is its low cost of generation and its non-damaging and noncorrosive properties. Previous studies have found that SOW is able to reduce the burden of MRSA and Acinetobacter spp on environmental surfaces when fogged. ${ }^{14}$ The microbiocidal activity of SOW in the presence of organic load has been demonstrated in previous studies. One study showed that SOW was rapidly effective in the presence of $1 \%$ horse serum against a variety of organisms including Escherichia coli, Pseudomonas aeruginosa and MRSA with kill rates comparable to $2 \%$ glutaraldehyde. ${ }^{15}$ Another study mentioned SOW to be equally effective under high and low soil conditions ( $1 \%$ and $5 \%$ horse serum) even against VRE. ${ }^{16}$ However, in other studies the biocidal activity of this disinfectant was substantially reduced in the presence of organic material. ${ }^{3}$ In this study, though SOW showed good activity against MDR Pseudomonas spp and VRE and its effects against these organisms were equally comparable to the others in presence of organic matter, yet effect of SOW was significantly reduced in presence of organic matter against MRSA. Therefore, it was concluded that if spillage occurs on a surface contaminated with MRSA, the inactivating effects of SOW is not sufficient. This could significantly limit the use of SOW in environments where MRSA is a common surface isolate.

Several studies have shown that the frequency of environmental contamination found in the rooms of patients with VRE varied between 7 and $37 \% .{ }^{17}$ Even if all colonized inpatients are successfully identified, VRE can spread by healthcare workers through either inadequate hand washing or contact with items like bedrails, sinks and doorknobs. ${ }^{18}$ Though all the disinfectants were effective against VRE, SOW, R82 and $70 \%$ ethyl alcohol were better.

Persistence of nosocomial pathogens on surfaces is an important parameter of assessing appropriate treatment of surfaces. ${ }^{4}$ The longer a nosocomial pathogen persists on a surface, the longer it may be a source of transmission. Data also demonstrate that important hospital acquired pathogens (VRE, MRSA) can survive on environmental surfaces for an extended period of time and this may allow for environmentally mediated disease transmission. ${ }^{3}$ Though the persistent effect amongst the tested disinfectants were not studied, SOW showed maximum effect at varying exposure times against all the organisms in clean conditions.

In India, cleanliness and disinfection practices vary drastically in different health care institutions. Majority of the health care institutions activities related to the housekeeping services including use of cleaning materials and disinfectants are done by personnel with 
little or no formal education. In most of the hospitals throughout the world, cleaning is often conducted by less skilled workers. ${ }^{3}$ In addition, there is no legislation, rules or agreements worldwide regarding the level of surface bacterial contamination deemed acceptable in hospitals. ${ }^{6}$ Disinfectants are often misused and rationalization of their use in hospitals is desirable for control both of infection and costs. ${ }^{19}$ Because strict contact isolation in a single room with barrier precaution seems to be impractical on already overstretched hospital resources, disinfection of inanimate environment of patients colonized or infected with multi-resistant organisms should be seriously taken into consideration. This study shows the effects of some of the newly introduced disinfectants and concludes that the choice of disinfectants should be based on the proper understanding of the organisms likely contaminating the surfaces and actions of each disinfectant on them. Disinfection policies should take into account the reasons and purposes for which disinfectants are used. The new guidelines on treatment of surfaces in hospitals, which take into account more parameters like type of ward and expected frequency of hand contact with a surface, ${ }^{4}$ could be truly beneficial in making a selection for the appropriate disinfectant.

\section{References}

1. Lemmen SW, Hafnera H, Zolldanna D, Stanzelb S, Lutticken R. Distribution of multi-resistant Gram-negative versus Grampositive bacteria in the hospital inanimate environment. J Hosp Infect 2004; 56: 191-197. http://dx.doi.org/10.1016/j. jhin.2003.12.004

2. Dettenkofer M, Wenzler S, Amthor S, Motschall E, Daschner FD. Does disinfection of environmental surfaces influence nosocomial infection rates? A systematic review. Am J Infect Control 2004; 32: 84-89. http://dx.doi.org/10.1016/j. ajic.2003.07.006

3. Rutala WA, Weber DJ. Surface disinfection: should we do it? J Hosp Infect 2001; 48: S64-S68. http://dx.doi.org/10.1016/ S0195-6701(01)90017-9

4. Kramer A, Schwebke I, Kampf G. How long do nosocomial pathogens persist on inanimate surfaces? A systematic review. BMC Infect Dis 2006; 6: 130. http://dx.doi.org/10.1186/14712334-6-130

5. Dancer SJ. How do we assess hospital cleaning? A proposal for microbiological standards for surface hygiene in hospitals. J Hosp Infect 2004; 56: 10-15. http://dx.doi.org/10.1016/j. jhin.2003.09.017
6. Comparison study on disinfectant efficiency of ethanol, bleach and anti-bacterial hand soap against $E$. coli and mixed culture. CE 773. http://www.cte.ku.edu/gallery/visibleknowledge/ sturm/files/Student $\% 20$ Work\%20Documents/final\%20 Lab\%20Project/group_b_report.pdf [last accessed on February 14, 2013].

7. Hedin G, Rynback J, Lore B. Reduction of bacterial surface contamination in the hospital environment by application of a new product with persistent effect. J Hosp Infect 2010; 30: 1-4.

8. Webster CA, Towner KJ. Use of RAPD-AFLP analysis for investigating the frequency of bacterial cross-transmission in an adult intensive care unit. J Hosp Infect 2000; 44: 254-260. http://dx.doi.org/10.1053/jhin.1999.0703

9. Weist K, Pollege K, Schulz I, Ruden H, Gastmeier P. How many nosocomial infections are associated with cross transmission? A prospective cohort study in a surgical intensive care unit. Infect Control Hosp Epidemiol 2002; 23: 127-132. http:// dx.doi.org/10.1086/502021

10. Kampf G, Kramer A. Epidemiologic background of hand hygiene and evaluation of the most important agents for scrubs and rubs. Clin Microbiol Rev 2004; 17: 863-893. http://dx.doi. org/10.1128/CMR.17.4.863-893.2004

11. Chaidez C, Lopez J, Campo NC. Quaternary ammonium compounds: an alternative disinfection method for fresh produce wash water. I Water Health 2007; 5: 329-333.

12. Maillard JY. Antimicrobial biocides in the healthcare environment: efficacy, usage, policies, and perceived problems. Ther Clin Risk Manag 2005; 1: 307-320.

13. Bhattacharya S. Is screening patients for antibiotic resistant bacteria justified in the Indian context? Indian J Med Microbiol 2011; 29: 213-217. http://dx.doi.org/10.4103/0255-0857.83902

14. Clark J, Barrett SP, Rogers M, Sapleton R. Efficacy of superoxidized water fogging in environmental decontamination. J Hosp Infect 2006; 64: 386-390. http:// dx.doi.org/10.1016/j.jhin.2006.07.019

15. Selkon JB, Babb JR, Morris, R. Evaluation of the antimicrobial activity of a new super-oxidized water, Sterilox, for the disinfection of endoscopes. I Hosp Infect 1999; 41: 59-70. http://dx.doi.org/10.1016/S0195-6701(99)90038-5

16. Shetty N, Srinivasan S, Holton J, Ridgway G. Evaluation of microbiocidal activity of a new disinfectant: Sterilox 2500 against Clostridium difficile spores, Helicobacter pylori, vancomycin resistant Enterococcus species, Candida albicans and several Mycobacterium species. J Hosp Infect 1999; 41: 101-105. http://dx.doi.org/10.1016/S0195-6701(99)90046-4

17. Weber DJ, Rutala WA. Role of environmental contamination in the transmission of vancomycin-resistant enterococci. Infect Control Hosp Epidemiol 1997; 18: 306-309. http://dx.doi. org/10.1086/647616

18. Huycke MM, Sahm DF, Gilmore MS. Multi-drug resistant enterococci: The nature of the problem and an agenda for the future. Emerg Infect Dis 1998; 4: 239-249. http://dx.doi. org/10.3201/eid0402.980211

19. Vij A, Kant S, Gupta S. Analytical evaluation of cleaning agents and disinfectants in use for housekeeping practices at a tertiary care hospital. J Acad Hosp Admin 2001; 13: 201-206. 